How The New York City School System, Its Teachers, Leadership, and Students Assured Health and Safety on 11 September 2001

D. Markenson; ${ }^{1}$ G. Thomas; ${ }^{1}$ N. Degnan ${ }^{2}$

1. National Center for Disaster Preparedness, Mailman School of Public Health, Columbia University, New York, New York USA

2. Columbia University, New York, New York USA

Tuesday, 11 September 2001 (9/11) presented the greatest emergency management challenge ever faced by a school district in the United States. The New York City Board of Education (BOE) had to evacuate eight schools and all 9,000 students within a quarter mile of the World Trade Center (WTC) and, additionally, ensure that all of the $>1$ million school children throughout New York City were safe, cared for, counseled, and safely returned home.

This presentation describes the BOE's response to the terrorist events of 9/11 and assesses the BOE's actions in maintaining the health and safety of New York City school children in the wake of the attack. It highlights the lessons learned, both successes and shortcomings, from the BOE's disaster plan and its actual response. The presentation specifically discusses how the BOE handled the safety, medical, and mental health needs as well as the evacuation procedure of the students, and the needs of special needs children, food and water issues, returning children to safety, and finally, issues of funding safety and recovery. It is important to note that while each section is presented separately, in reality, there is a concentric nature to each of the elements discussed.

This study was a purposeful sample of decision-makers and crisis management professionals at the BOE. Semistructured interviews were conducted by trained interviewers. Member checks were conducted to establish the accuracy of the information recorded, and participants were able to modify their comments where necessary. Secondary research was conducted through the analysis of BOE documents, memos, directives, and news articles, in addition to federal, state, and municipal agency reports.

The magnitude and scope of the $9 / 11$ events far surpassed any contingency defined in each school's safety plan. Understanding how the BOE responded to the challenges of $9 / 11$ represents an important contribution to the knowledge of disaster planning in general and is a new chapter in evaluating the success, limitations, and recommended practices of schools' safety/emergency planning and response. Keywords: 11 September 2001 ( $9 / 11)$; assessment; children; disaster; New York City; response; safety; terrorism Prehosp Disass Med 2005;20(2): 533

\section{Medical Care to Children in Disasters in Russia}

\section{Petlakb; ${ }^{1}$ S.F. Goncharov; ${ }^{2}$ V.M. Rozinov: ${ }^{1}$}

V.E. Shabanov ${ }^{2}$

1. Moscow Scientific Research Institute of Paediatric, Moscow, Russia

2. All-Russian Centre of Disaster Medicine "Zaschita," Moscow, Russia

Introduction: The organization and provision medical aid to children in extreme situations represents a priority task of National Service of Disaster Medicine, as children represent $20-45 \%$ of all victims.

Methods: Organizational forms of providing of medical aid to children in disasters include: (1) Mobile Pediatric Brigades (İPB); (2) the pediatric unit in structure of the Field Multi-profile Hospital (FMH) of the All-Russia Center of Disaster Medicine (ARCDM) "Zaschita"; and (3) the Children Field Hospital (CFH) ARCDM "Zaschita".

Results: The İPB worked successfully in clinics of Armenia, Ufa, and Vladikavkaz. In Armenia, 2,645 children with various injuries have been hospitalized. In Ufa (1989), 125 children with burns were treated in hospitals. In Northern Ossetia (1992), 151 wounded men have been hospitalized, $87 \%$ from gunshot wounds. The pediatric unit of the FMH, set up in Mozdok and Grozny (1994-1995), is made up of 50\% of the doctors on the hospital staff. During a 14-month span in 2001-2002 in the Gudermes area of the Chechen Republic, the Childrens Field Hospital performed 32,300 out-patient consultations, treated $>28,000$ patients, and performed $>2,000$ surgical operations. After the terrorist event in Beslan (Northern Ossetia, 2004), 311 children were admitted to $\mathrm{CFH}$, and 47 surgical operations were performed. The ARCDM staff evacuated 135 children to clinics in Moscow. The work of the MPB consisted of medical triage, providing diagnostic help (advisory and medical) to local hospitals, and medical escort during air evacuations. In the FMH, emergency medical aid was provided and patients were evacuated to the nearest hospitals. In the $\mathrm{CFH}$, there were specialized kinds of medical aid provided, including complex, scheduled surgical operations and tele-medicine consultation.

Conclusion: The National Service of Disaster Medicine has provided the structural medical formation of a pediatric profile that depends on the features of medical-tactical conditions, which is necessary in order to realize the most effective model for providing qualified and specialized medical aid to children in various extreme situations.

Keywords: aid; children; field; hospitals; medical aid; Russia; staff; tactics

Prebosp Disast Med 2005;20(2):s33

\section{Helping Children in Disasters through Alleviating Their Parent's Anxiety: Psychosocial Group Interventions Post-Disaster}

D. Markenson; P. Madrid; I. Redlener

National Center for Disaster Preparedness, Columbia University, New York, New York USA

In the aftermath of the terrorist attacks on 11 September 2001 , concerns in the local community with the World Trade Center site included relocation, air quality, and a sense of no longer feeling safe. Despite evidence of anxiety and depression, there were delays and barriers in seeking mental health interventions. Approximately 9,000 students who attended seven local schools were moved from one temporary school location to another, some for seven months before the local school was deemed ready to reoccupy. Many of these children were eyewitnesses to the hor- 
rifying events of 11 September (Dorn, Thomas, Wong, and Shepherd, 2004). Once they returned to their homes, the residents of lower Manhattan were reminded of the catastrophe as they waked through their neighborhoods or looked out their windows. Transportation into and out of lower Manhattan was difficult.

In an attempt to meet the needs of this directly affected community, a program was established to help children through psychosocial interventions directly offered to parents. Free, confidential, easily accessed services were offered. Parents sought information about typical posttrauma responses and how to manage their children's and their own stress and anxiety. A support group for mothers who were residents of Battery Park City was started and met weekly beginning 02 December 2001 in private rooms in local coffee houses (Madrid, Grant, Markenson, under review). This faciliated easy access while maintaining confidentiality. Initial client concerns were anxiety, marital discord, and how to discuss the event with their children. Within six months, anxiety was notably reduced and members reported a sense of having mastered skills to help their children. Following a disaster, psychotherapy delivered in non-traditional settings may help overcome barriers and resistance. It is essential to keep in mind that engaging parents in coping behaviors and understanding of issues impacting their children's well-being will positively impact their children. Providers should be flexible and prepared to meet emerging needs.

Keywords: 11 September 2001; children; coping strategies; disaster; New York; parents; psychotherapy

Prehosp Disast Med 2005;20(2):s33-s34

\section{Free Papers Theme 10: Resuscitation}

\section{Evaluation of the Effects of a National Disaster Life Support (NDLS) Preparedness Curriculum on 800 Participants in Dallas and Fort Worth, Texas \\ G.L. Larkin; ${ }^{1}$ R. Swienton; ${ }^{1}$ R.P. Smith, ${ }^{2}$ P.E. Pepe ${ }^{1}$ \\ 1. University of Texas Southwestern Medical School, Dallas, Texas USA \\ 2. Mount Sinai Hospital, New York, New York USA}

Introduction: The National Disaster Life Support (NDLS) curriculum was developed by the American Medical Association with input from key academic and governmental institutions. The NDLS program emphasizes multidisciplinary, all-hazards training (e.g., for healthcare providers, emergency workers, first responders, and municipal workers), with a focus on the general improvement of public health preparedness and response infrastructures, operating at individual and system levels. Three stand-alone courses provide didactic and practical "hands-on" experiences using simulation and role-play. An evaluation component was designed according to Bloom's taxonomy of adult learning to assess the effects of this curriculum on knowledge base (via written exam), psychomotor skills base (via simulations and role-play), and level of engagement (increases in confidence, interest, and willingness to volunteer, e.g., in the National Disaster Medical Corps).
Methods: In a quasi, experimental, pre- and post-test, longitudinal, cohort design, 800 participants in the trainings were evaluated immediately before and after the training, and six months after the completion of the training.

Results: Knowledge base, as measured by scores on written examinations increased from $30 \pm 5 \%$ before the course to $68 \pm 20 \%$ at its conclusion. More than $80 \%$ of participants achieved satisfactory performance on psychomotor tasks such as ability to select and don appropriate protective gear properly. Self-ratings of confidence in knowledge base as "high or very high" increased from $5 \pm 4 \%$ before the course to $45 \pm 10 \%$ at its conclusion.

Conclusions: More detailed analyses, including the ongoing effects of receiving continued education via quarterly "booster" training sessions, and web-based programs must be assessed to permit evaluation.

Keywords: assessment; education; evaluation; National Disaster Life Support (NDLS); preparedness; training Prebosp Disast Med 2005;20(2):s34

\section{Prehospital First-Aid in Shanghai \\ K. Cha $i^{1}$ W. Guo ${ }^{2}$ \\ 1. Nan Fang University, China \\ 2. Jinjiang Hospital, China}

Shanghai is one of the biggest cities in the world, with a population of 13 million. The average density of the population is $>1,000$ persons per square kilometer. Deaths and the injuries from disasters in Shanghai from 1949 to 2003 are shown in Table 1.

The First-Aid Central Station of Shanghai (SFACS) has 173 ambulances and 517 specialists. The equipment of the new resuscitation ambulances, so-called "Movable ICUs", contains a cardiopulmonary monitor, ventilator, emergency drugs, and other resuscitative equipment. In the ambulance, there also is excellent communication equipment, which can connect with any part of the communication network in the city of Shanghai. In 1998, a total of 110,889 persons requiring first-aid were transported by the SFACS. The number injured in traffic crashes and other disasters during this time was 26,681 , of which 318 died before hospitalization. All severe trauma patients should be transported to an identified hospital in Shanghai.

\begin{tabular}{|l|r|r|r|}
\hline \multicolumn{1}{|c|}{ Disaster } & Occurrence & Death & Wounded \\
\hline Traffic crash & 600,000 & 19,391 & 286,117 \\
\hline Fire & 31,101 & 517 & 1,053 \\
\hline Earthquake & 19 & 9 & 92 \\
\hline Typhoon & 102 & 2,086 & 2,672 \\
\hline Rainstorms & 117 & 32 & 105 \\
\hline Fog & 66 & 23 & 121 \\
\hline Air crashes & 3 & 42 & 71 \\
\hline
\end{tabular}

Table 1-Disaster-related morbidity and mortality in Shanghai from 1949 to 2003

Keywords: First-Aid Central Station of Shanghai (SFACS); prehospital; resuscitation; Shanghai Prebosp Disast Med 2005;20(2):s34 